\title{
Impact of Perceived Risk on Online Impulse Buying Tendency: an Empirical Study in the Consumer Market of Pakistan
}

\author{
Kashif Abrar*, Muhammad Naveed and Muhammad I Ramay
}

Department of Management Sciences, Bahria University, Islamabad, Pakistan

\begin{abstract}
The purpose of this paper was to investigate influence of perceived risk (financial risk, product risk, convenience risk and non-delivery risk) on online impulse buying tendency. Web-based survey was conducted for data collection using online questionnaire distributed through stratified random sampling technique from online consumers of Pakistan. A total of 200 valid responses were gathered and the data was analyzed by using SPSS software and demographic statistics, correlation and regression tests. The proposed hypotheses were confirmed through data analysis results. Overall perceived risk, financial risk and product risk were found to have a moderately negative association with online impulse buying tendency whereas convenience risk and non-delivery risk had negative but weaker association with online impulse buying tendency.
\end{abstract}

Keywords: Online impulse buying tendency; Perceived risk; Product risk; Financial risk; Convenience risk; Non-delivery risk; Online consumer behavior; Pakistan

\section{Introduction}

The success of ecommerce has paved ways for elaborative research to understand consumer behavior in online context. Marketing philosophers and practitioners are interested in gaining insights to all factors that influence online purchasing and how these shopping patterns are formed. The most influential aspect that encourages consumers to buy their desired products online is convenience, since online stores are operational 24/7 and it is easier to compare products offered by numerous sellers worldwide [1]. As compared to traditional shopping, consumers do not have to face issues like store location and product availability while shopping online [2]. The advantages offered by online shopping are favoring consumers but quite often they encourage impulsiveness in online decision making which is beneficial for vendors [3]. Ecommerce is growing at rapid pace which makes a deeper understanding of impulse purchasing over the internet progressively significant [4].

Impulsive purchasing behavior is generally referred to as a rapid, persuasive and hedonically complex buying behavior that does not involve thoughtful consideration of alternate choices and existing information [5]. Significant research studies have been conducted on factors influencing impulse buying in traditional stores, however, from the perspective of online stores; the research on this important construct has been limited. The phenomenon of online impulse buying behavior has gained popularity in recent times since researchers are actively exploring new dimensions of consumer behavior that affect impulse buying in online context [6]. Consumers are more likely to overspend money while shopping online due to special attributes associated to virtual transactions thus merchants are often able to generate high profits as a result of online impulse buying behavior of their consumers [7]. The tendency to buy impulsively turns out to be a very strong predictor that encourages impulse buying behavior [8].

Impulse buying tendency can be defined as the extent to which a person is likely to make instantaneous, unintentional and unreflective purchase [9]. Buying impulsive tendency is not only a basic human trait, but it also varies from person to person [10]. There can be several aspects that hinder the impulse buying tendency to turn into actual purchase behavior; one of them is the risk perception by consumer while shopping online [11]. The risk perception in any form including fear of getting personal information getting leaked out, not being able to examine the product physically, not getting physical exposure to the outlet and the risk of not getting exactly same product as displayed on the virtual store might significantly affect the purchasing behavior of online consumers [12]. Although, a comprehensive understanding of how perceived risk influences impulse buying tendency in online context is essential for marketers to gain competitive advantage, literature pertaining to this domain is scarce. The present study attempts to fill out this gap in literature by investigating the relationship between perceived risk and online impulse buying tendency from the perspective of a developing country, Pakistan.

The current study is of significant importance since it specifically focuses on impulse buying tendency instead of impulse buying behavior and that too in online context, contrary to most of previous studies that have targeted impulse buying behavior in traditional and online shopping. This paper begins with a review of literature on online impulse buying tendency and perceived risk. After that a theoretical framework is established followed by proposed hypotheses. Methods for data collection and hypotheses testing are discussed leading to results and discussion. The paper concludes with discussing theoretical and practical implications and directions for future research.

\section{Literature Review}

\section{Online impulse buying tendency}

Rook and Fisher [9] identified impulse buying tendency to be a basic characteristic of consumers. This phenomenon has been comprehensively defined as "a consumer's tendency to buy spontaneously, unreflectively, immediately, and kinetically". Impulse

*Corresponding author: Kashif Abrar, Ph.D. Scholar, Department of Management Sciences, Bahria University, Islamabad, Pakistan, Tel: +923455551579; E-mail: kashif_411@hotmail.com

Received July 24, 2017; Accepted July 27, 2017; Published August 04, 2017

Citation: Abrar K, Naveed M, Ramay MI (2017) Impact of Perceived Risk on Online Impulse Buying Tendency: an Empirical Study in the Consumer Market of Pakistan. J Account Mark 6: 246. doi: 10.4172/2168-9601.1000246

Copyright: (๑) 2017 Abrar K, et al. This is an open-access article distributed under the terms of the Creative Commons Attribution License, which permits unrestricted use, distribution, and reproduction in any medium, provided the original author and source are credited. 
buying tendency is a strong predictor of actual purchase behavior and as this tendency increases, the likelihood of consumers indulging into impulse buying behavior also increases [13]. The motivation behind consideration of impulse buying tendency instead of impulse buying behavior for the purpose of this research is that tendency to buy impulsively is a representation of how different consumers think and act distinctly in an identifiable manner [14]. The reaction in response to a sudden impulse to buy is very strong by some people while others don't react at all. Those with a high inclination towards sudden impulse have openness towards unanticipated purchasing ideas and quite often find instant delight and emotional attraction towards the product [9]. Although, this makes it pretty simple to understand that consumers with high level of impulse buying tendency will positively respond to buying impulses, this relationship is not straight forward since several factors might restrain this tendency to turn into actual behavior. In other words, even the consumers with high impulse buying tendency might not be showing impulse buying behavior all the times due to numerous factors like time pressure, economic feasibility and social influence [15].

There is a positive association of impulse buying tendency with lack of control, stress reaction and absorption [16]. Cultural values are observed to have a significant influence over buying impulsive tendency since this tendency has a stringer linkage with impulse behavior in individualistic culture as compared to collectivistic culture [17]. Impulse buying tendency is found to have a strong correlation with age and availability of pocket money [18]. Impulse buying exists over the internet as well; however the tendency to buy impulsively might be somewhat different in online context as compared to conventional stores due to special traits accompanying online shopping. For example, risk perception about the product is very different while shopping online than traditional shopping. Prior studies on impulse buying tendency have primarily focused on factors that are positively associated with buying impulsive tendency, developed countries and offline context. In the present study, focus is on factors that might hinder tendency to buy impulsively online from the perspective of a developing country in an attempt to contribute towards consumer behavior literature.

\section{Perceived risk}

Perceived risk can be explained as consumer's consciousness of insecurity and contradictory consequences as a result of buying a product or service [19]. Peter and Tarpey [20] defined it as "The probability that the purchase of the product will result in the displeasure of the consumer". There are more risks and suspicions associated with online shopping than offline context [21]. There are different components of risk perception [22] but for the purpose of current study financial risk, product risk, convenience risk and nondelivery risk have been considered as dimensions of risk perception for a comprehensive understanding. The perceived risk is found to negatively influence consumer's online shopping intentions [23,24] whereas lower level of risk perception leads to preference of online shopping [25,26]. It is hypothesized that overall perceived risk has a negative relationship with online impulse buying tendency.

\section{Financial risk}

The probability of suffering monetary loss as a result of purchasing a product or service is termed as financial risk [27]. Online consumers are concerned about their credit card information getting leaked out or they might get over charged by the vendors. Financial risk also refers to probability of not getting the lowest possible price for the selected product from a particular online store [28]. Previous studies have identified a negative relationship between financial risk and intention to purchase online $[28,29]$. It is therefore hypothesized that perceiving financial risk has a negative linkage with online impulse buying tendency.

\section{Product risk}

Peter and Tarpey [20] explained product risk as the likelihood that the chosen product will fail to meet the formerly anticipated requirements. Online consumers might be doubtful about whether or not they will be delivered exactly the same product as displayed on the online store or it might not come up to their expectations. Higher the intangibility of the product, greater will be the risk perception [30,31]. Frequency of online shopping is significantly influenced by perceived product risk [32]. For certain product categories, the level of insecurity negatively affects the buyer's intention to make a purchase decision online $[33,34]$. The review of literature suggests that a negative relationship between product risk and online impulse buying tendency can be hypothesized.

\section{Convenience risk}

The potential loss of time while searching, comparing and buying products online is described as convenience or time risk. Convenience risk can be referred to as loss of time taken by the website pages to download which can be irritating for online consumers [32] and it is also explained as difficulty in operating the website that might be caused due to an online store which is difficult to navigate or provides ambiguous information about the products [35]. Although, perceived convenience risk does not have a stronger influence over online purchase behavior as compared to other dimensions of perceived risk such as financial and product risk, still it has a considerable impact over adoption to ecommerce [36,37]. It can be hypothesized that perceived convenience risk has a negative relationship with online tendency to buy impulsively.

\section{Non-delivery risk}

The probability of not getting the product after completing online transaction and making payment to the online store is described as non-delivery risk. Consumers quite often find uncertainty while dealing with relatively new online merchants while making payments due to risk that vendors will not deliver the product to them. Few studies in the domain of online consumer behavior have found a significant and negative influence of non-delivery risk over online buying behavior [38]. Based on previous findings, it is hypothesized that perceiving non-delivery risk has a negative influence over online impulse buying tendency.

\section{Conceptual Framework}

The proposed conceptual framework for present study comprises of four independent and one dependent variable. The four independent variables are dimensions of perceived risk which are financial risk, product risk, convenience risk and non-delivery risk. All these dimensions add up to give a combined effect of overall perceived risk. The only dependent variable in the framework is online impulse buying tendency (Figure 1).

\section{Methodology}

The study followed positivist paradigm, deductive approach and quantitative techniques as adopted by few other studies in the similar domain $[4,39,40]$. Data were collected at one point in time so time horizon was cross sectional. 
Independent Variables $\quad$ Dependent Variable

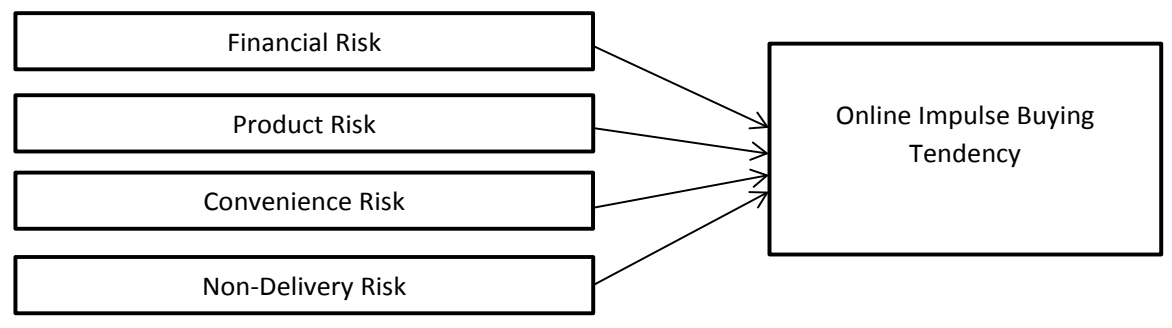

Figure 1: Conceptual Framework.

\begin{tabular}{|l|l|l|l|}
\hline Variable & No. of items & Items source & Recently validated \\
\hline Online impulse buying tendency & 7 & Verplanken and Herabadi [46] & Ozen and Engizek [47] \\
\hline Financial Risk & 3 & Swinyard and Smith [48], Forsythe et al. [29] & Moshrefjavadi et al. [38] \\
\hline Product Risk & 3 & Swinyard and Smith [48], Forsythe et al. [29] & Moshrefjavadi et al. [38] \\
\hline Convenience Risk & 6 & Swinyard and Smith [48], Forsythe et al. [29] & Moshrefjavadi et al. [38] \\
\hline Non-delivery Risk & 2 & Forsythe et al. [29] & Moshrefjavadi et al. [38] \\
\hline
\end{tabular}

The variables were accounted for by using 5 point Likert scale indicating 1: Strongly disagree; 2: Disagree; 3: Neutral; 4: Agree; 5: Strongly agree

Table 1: Variables, number of items and sources and recent validation.

\section{Population and sample size}

Target population for this study was online consumers from Pakistan. For research in business, sample size of 30 to 500 is considered enough [41]. Considering comprehensiveness of results as well as time and budget constraints, the sample size determined for this study was 200 .

\section{Instrument and measurement}

For the purpose of data collection, a 25 items online questionnaire was prepared using scales for measuring selected variables adapted from reliable and validated sources. 3 questions were related to demographic information like age, gender and qualification. 1 question was intentionally added to ensure that respondents had prior online shopping experience. 21 items were adapted from established scales to measure independent and dependent variables. Table 1 shows number of items for measuring each variable and sources of these items and which recent studies have validated these scales.

\section{Procedure and sampling technique}

Data for the present study were collected using an online questionnaire distributed through stratified random sampling technique on Facebook and google groups. Groups representing educational institutions were considered for data collection. Web survey approach was selected for gathering responses since it is better than many conventional methods in terms of saving time and cost [42]. The nature of this study also made it feasible to opt for web survey. Online questionnaire was posted on Facebook and Google groups and members of these groups were invited to fill the questionnaire through private messages as well until the desired 200 useable responses were collected. Participation in the online survey was voluntary and no monetary or non-monetary benefits were offered. Participants were able to fill the questionnaire only once and no changes were allowed to be made in their response after submitting the form online. Data was then analyzed using SPSS (version 21) software.

\section{Results and Findings}

The purpose of the present study was to identify the relationship between perceived risk and online impulse buying tendency. In order

\begin{tabular}{|l|l|l|l|l|}
\hline S. No. & Variable & Items & N & Cronbach's Alpha \\
\hline 1 & Financial risk & 3 & 200 & 0.739 \\
\hline 2 & Product risk & 3 & 200 & 0.712 \\
\hline 3 & Convenience risk & 6 & 200 & 0.787 \\
\hline 4 & Non-delivery risk & 2 & 200 & 0.656 \\
\hline 5 & Overall perceived risk & 14 & 200 & 0.902 \\
\hline 6 & Online impulse buying tendency & 7 & 200 & 0.835 \\
\hline
\end{tabular}

Table 2: Reliability analysis of variable instrument measures.

to investigate the relationship between proposed variables, different tests were executed and the results have been gathered and summarized in Tables 2-7. Frequency distribution with respect to sample profile and inferential statistics (Cronbach's Alpha, Pearson Correlation and Regression) were used for data analysis through Statistical Package for Social Sciences software (SPSS).

\section{Reliability and demographic analysis}

Items of the questionnaire for this research were adopted from established scales but these items were slightly modified to the context of present study. Therefore, reliability analysis was performed to analyze the fidelity of the instrument measures.

Cronbach's Alpha values for all independent and depend variables have been shown in Table 2. When the value of Cronbach Alpha is greater than 0.7, this indicates higher internal consistency of the data [43]. Cronbach Alpha values for financial risk, product risk, convenience risk, overall perceived risk and online impulse buying tendency is greater than 0.7 however, for non-delivery risk, this value is slightly less than the suggested level.

The total number of observations (N) for the present study was 200 . Frequency of gender, age and level of education of respondents has been summarized in Table 3. Considering gender, most of the respondents were females comprising of $60 \%$ of the sample. Analyzing age groups, maximum response came from participants belonging to age group of 26-30 years with $30 \%$ and not very far behind was age group of 21-25 years with $26 \%$ responses out of the total sample. When it comes to educational level, highest participation was from MS/M.Phil. degree holders constituting $38 \%$ of the total number of observations. 


\begin{tabular}{|l|l|c|c|c|c|}
\hline Demographic & Characteristics & Frequency & Percent & $\begin{array}{c}\text { Valid } \\
\text { percent }\end{array}$ & $\begin{array}{c}\text { Cumulative } \\
\text { percent }\end{array}$ \\
\hline Gender & Male & 80 & 40 & 40 & 40 \\
& Female & 120 & 60 & 60 & 100 \\
\hline Age & $16-20$ & 24 & 12 & 12 & 12 \\
& $21-25$ & 52 & 26 & 26 & 38 \\
& $26-30$ & 60 & 30 & 30 & 68 \\
& $31-35$ & 20 & 10 & 10 & 78 \\
& $36-40$ & 24 & 12 & 12 & 90 \\
& $41+$ & 20 & 10 & 10 & 100 \\
\hline Educational & Intermediate & 40 & 20 & 20 & 20 \\
& Graduate & 36 & 18 & 18 & 38 \\
& Masters & 36 & 18 & 18 & 56 \\
& MS/M.Phil & 76 & 38 & 38 & 94 \\
& Ph.D & 12 & 6 & 6 & 100 \\
\hline
\end{tabular}

Table 3: Frequency distribution with respect to "sample profile".

\begin{tabular}{|l|l|l|l|l|l|l|}
\hline Variable & FR & PR & CR & NDR & OPR & OITB \\
\hline FR & 1 & & & & & \\
\hline PR & $.992^{\star *}$ & 1 & & & & \\
\hline CR & $.564^{* *}$ & $.537^{* *}$ & 1 & & & \\
\hline NDR & $.501^{* *}$ & $.473^{\star *}$ & $.867^{* *}$ & 1 & & \\
\hline OPR & $.873^{* *}$ & $.857^{* *}$ & $.889^{* *}$ & $.817^{* *}$ & 1 & \\
\hline OITB & $-.558^{\star *}$ & $-.553^{* *}$ & $-.348^{\star *}$ & $-.225^{\star *}$ & $-.498^{\star *}$ & 1 \\
\hline
\end{tabular}

${ }^{* *}$ Correlation is significant at the 0.01 level (2-tailed)

Table 4: Negative correlation between all independent variables.

\section{Correlation analysis}

Table 4 highlights that there exists a negative correlation between all independent variables (financial risk (FR), product risk (PR), convenience risk (CR), non-delivery risk (NDR) and overall perceived risk $(\mathrm{OPR})$ ) and the dependent variable (online impulse buying tendency (OITB)) at $1 \%$ level of significance.

Pearson correlation value between financial risk and online impulse buying tendency is -0.558 with significant $p$ value $(0.000)$. This indicates that there is a moderately negative correlation between financial risk and online impulse buying tendency. The value of Pearson correlation between product risk and online impulse buying tendency is -0.553 with significant $\mathrm{p}$ value $(0.000)$ again showing a moderate negative correlation between the two variables. For convenience risk and non-delivery risk, the Pearson correlation value is -0.348 and -0.225 respectively with significant $p$ value $(.000)$ identifying a negative but weak correlation of these variables with online impulse buying tendency. Overall perceived risk is found to have a negative and moderate correlation with online impulse buying tendency having Pearson correlation value of -0.498 with significant $p$ value $(0.000)$.

The results of correlation analysis shown in Table 4 indicate that the strongest correlation of online impulse buying exists with financial risk and weakest correlation exists with non-delivery risk.

\section{Regression analysis}

To determine the extent to which online impulse buying tendency is influenced by the selected independent variables, regression test was applied. In Table 5, the value of coefficient of determination " $\mathrm{R}$ " shows the extent of variation caused by the independent variables.

$\mathrm{R}^{2}$ value for financial risk is 0.558 . This means that there is $55.8 \%$ variation in online impulse buying tendency of online consumers due to perceived financial risk. Similarly $\mathrm{R}^{2}$ value for product risk is 0.553 , for convenience risk is 0.348 and for non-delivery risk it is 0.225 . The overall perceived risk has coefficient of determination value of 0.498 depicting that risk perception attributes for $49.8 \%$ change

\begin{tabular}{|l|c|c|c|c|}
\hline Variable & $\mathbf{R}$ & R square & $\begin{array}{c}\text { Adjusted R } \\
\text { square }\end{array}$ & $\begin{array}{c}\text { Std. error of } \\
\text { the estimate }\end{array}$ \\
\hline Financial risk & 0.558 & 0.311 & 0.308 & 0.64195 \\
\hline Product risk & 0.553 & 0.306 & 0.302 & 0.64436 \\
\hline Convenience risk & 0.348 & 0.121 & 0.117 & 0.72510 \\
\hline Non-delivery risk & 0.255 & 0.065 & 0.060 & 0.74785 \\
\hline Overall perceived risk & 0.498 & 0.248 & 0.244 & 0.67079 \\
\hline
\end{tabular}

Dependent variable: online impulse buying tendency

Table 5: Model summary.

\begin{tabular}{|l|c|c|c|c|}
\hline Variable & $\begin{array}{c}\text { Standardized } \\
\text { coefficient beta }\end{array}$ & t value & F value & Sig. \\
\hline Financial risk & -0.558 & 20.161 & 89.374 & 0.000 \\
\hline Product risk & -0.553 & 19.540 & 87.227 & 0.000 \\
\hline Convenience risk & -0.348 & 12.972 & 27.245 & 0.000 \\
\hline Non-delivery risk & -0.255 & 12.076 & 13.745 & 0.000 \\
\hline Overall perceived risk & -0.498 & 16.110 & 65.196 & 0.000 \\
\hline
\end{tabular}

Dependent variable: online impulse buying tendency

Table 6: Coefficients

in online impulse buying tendency and $50.2 \%$ fluctuation is due to other mysterious factors. When consumers perceive risk in an online transaction, their tendency to buy impulsively decreases by almost $50 \%$.

Table 6 illustrates that there is a negative relationship between independent variables and the dependent variable. The $t$ value is greater than 2 for all variable indicating considerable influence of the variables. Overall regression model is statistically significant since $\mathrm{F}$ value is greater than 4 for all variables. Results summarized in Table 6 support all the proposed hypotheses that financial risk, product risk, convenience risk, non-delivery risk and overall perceived risk have a negation association with online impulse buying tendency.

The results of all proposed hypotheses for current study have been summarized in Table 7 . The correlation and regression analysis of the collected data indicates that all hypotheses have been upheld. The proposed model has a negative relationship with online impulse buying tendency which signifies the importance of the present study. The selected variables can be considered as prominent factors to study consumer behavior in online context.

\section{Discussions}

The present study was one of the rare efforts to highlight an important attribute of consumer behavior that is online impulse buying tendency from the context of developing economies. Although lack of prior literature in the similar domain makes it difficult to compare results of this research with previous findings, it can be linked to some previous researches on online consumer behavior with respect to risk perception. Few researches on online consumer behavior have identified a negative and strong influence of risk perception on intention of online purchasing [35,44-48]. However, this study has identified a moderate negative association between risk perception and online impulse buying tendency. More research work needs to be carried out in developing and developed countries for a comprehensive understanding of how risk perception affects online consumer behavior and more specifically their tendency to buy impulsively.

\section{Conclusion}

The paper is among few attempts to study online impulse buying tendency from the perspective of a developing country. Prior literature lacks a comprehensive investigation of the relationship between perceived risk and online impulse buying tendency in Pakistani 


\begin{tabular}{|l|l|l|l|}
\hline S. No. & Hypothesis & Statement of hypothesis & $\begin{array}{l}\text { Supported/not } \\
\text { supported }\end{array}$ \\
\hline 1 & $\mathrm{H}_{1}$ & There is a negative relationship between Overall Perceived Risk and Online Impulse Buying Tendency. \\
\hline 2 & $\mathrm{H}_{1 \mathrm{a}}$ & There is a negative relationship between Financial Risk and Online Impulse Buying Tendency. & Supported \\
\hline 3 & $\mathrm{H}_{1 \mathrm{~b}}$ & There is a negative relationship between Product Risk and Online Impulse Buying Tendency. & Supported \\
\hline 4 & $\mathrm{H}_{1 \mathrm{c}}$ & There is a negative relationship between Convenience Risk and Online Impulse Buying Tendency. & Supported \\
\hline 5 & $\mathrm{H}_{1 \mathrm{~d}}$ & There is a negative relationship between Non-Delivery Risk and Online Impulse Buying Tendency. \\
\hline
\end{tabular}

\section{Table 7: Results of hypotheses testing.}

consumer market. The present study has contributed to existing body of knowledge by focusing on impulse buying tendency only in online context. The phenomenon of online shopping has gained popularity in Pakistan in recent times. Being a developing economy with low literacy rate, there are lots of reservations linked with online consumer behavior in Pakistan and one of them is risk perception. The present study has identified few important factors like financial risk and product risk that have a relatively stronger influence over online impulsive tendency of consumers in Pakistan. Marketers should try to convince and build trust among their consumers that they will be getting exactly the same product as displayed on their online stores and it will come up their expectations as well. This can be done by adding testimonials, reviews and comments from previous buyers related to online store and product quality. Also navigation on website and comparing prices for the products should be made feasible for consumers so that their risk perception can be minimized. Online consumers in Pakistan are generally reluctant to give out their credit card information to online merchants; therefore online vendors should offer different payments options such as cash on delivery so that their perception of online fraud due to credit card misuse can be minimized. Some online shopping websites in Pakistan are already offering multiple payment options to their clients. Although, non-delivery risk is found to have least influence over online impulse buying tendency, online vendors should focus timely delivery to ensure competitive advantage. Impulse buying tendency is more likely to turn into impulse buying behavior which is beneficial for merchants so efforts should be made to minimize the risks associated with online transactions.

\section{Limitations and Directions for Future Research}

The findings of the present study suggest that there is almost $50 \%$ reduction in online impulse buying tendency due to risk perception. Future studies should investigate those mysterious factors that cause the other $50 \%$ variation. The study is limited to Pakistan only with sample size of 200 respondents due to time and budget constraints, similar research can be repeated in other cultures with a greater sample size to get more generalized outcomes. The present study has considered limited dimensions for perceived risk, future studies might consider adding other dimensions of perceived risk along with existing ones for better and comprehensive analysis of influence of perceived risk on online impulse buying tendency. The study is not industry specific, further studies in a particular industry might produce more precise outcomes.

\section{References}

1. Kim YK (2002) Consumer value: an application to mall and internet shopping International Journal of Retail and Distribution Management 30: 595-602.

2. LaRose $R$ (2001) On the negative effects of e-commerce: A sociocognitive exploration of unregulated on-line buying. Journal of Computer-Mediated Communication 6.

3. Dawson S, Kim M (2009) External and internal trigger cues of impulse buying online. Direct Marketing: An International Journal 3: 20-34.

4. Floh A, Madlberger M (2013) The role of atmospheric cues in online impulsebuying behavior. Electronic Commerce Research and Applications 12: 425-439.
5. Parboteeah DV, Valacich JS, Wells JD (2009) The influence of website characteristics on a consumer's urge to buy impulsively. Information Systems Research 20: 60-78.

6. Park EJ, Kim EY, Funches VM, Foxx W (2012) Apparel product attributes, web browsing, and e-impulse buying on shopping websites. Journal of Business Research 65: 1583-1589.

7. Dittmar H, Long K, Meek R (2004) Buying on the internet: gender differences in on-line and conventional buying motivations. Sex roles 50: 423-444.

8. Zhang X, Prybutok VR, Strutton D (2007) Modeling influences on impulse purchasing behaviors during online marketing transactions. Journal of Marketing Theory and Practice 15: 79-89.

9. Rook DW, Fisher RJ (1995) Normative influences on impulsive buying behavior Journal of Consumer Research 305-313.

10. Dittmar H, Drury J (2000) Self-image - is it in the bag? A qualitative comparison between 'ordinary' and 'excessive' consumers. Journal of Economic Psychology 21: 109-142.

11. Brosdahl DJ, Almousa M (2013) Risk perception and internet shopping: comparing United States and Saudi Arabian consumers. Journal of Management and Marketing Research 13: 1-17.

12. Ko H, Jung J, Kim J, Shim SW (2004) Cross-cultural differences in perceived risk of online shopping. Journal of Interactive Advertising 4: 20-29.

13. Hanzaee KH, Taherikia F (2010) Impulse buying: an Iranian model. China-USA Business Review 9: 31

14. Beatty SE, Ferrell ME (1998) Impulse buying: Modeling its precursors. Journal of retailing 74: 169-191.

15. Kwak H, Zinkhan GM, DeLorme DE, Larsen T (2006) Revisiting normative influences on impulsive buying behavior and an extension to compulsive buying behavior: A case from South Korea. Journal of International Consumer Marketing 18: 57-80.

16. Youn S, Faber RJ (2000) Impulse buying: its relation to personality traits and cues. ACR North American Advances.

17. Kacen JJ, Lee JA (2002) The influence of culture on consumer impulsive buying behavior. Journal of consumer psychology 12: 163-176.

18. Chien-Huang $L$, Hung-Ming $L$ (2005) An exploration of Taiwanese adolescents 'impulsive buying tendency. Adolescence 40: 215.

19. Dowling GR, Staelin R (1994) A model of perceived risk and intended riskhandling activity. Journal of Consumer Research 21: 119-134.

20. Peter JP, Tarpey Sr LX (1975) A comparative analysis of three consumer decision strategies. Journal of Consumer Research 2: 29-37.

21. Li YH, Huang JW (2009) Applying theory of perceived risk and technology acceptance model in the online shopping channel. World Academy of Science, Engineering and Technology 53: 919-925.

22. Kim M, Lennon SJ (2000) Television shopping for apparel in the United States: Effects of perceived amount of information on perceived risks and purchase intentions. Family and Consumer Sciences Research Journal 28: 301-331.

23. Clark TH, Lee HG (1996) Economic benefits and adoption barriers of electronic market systems. InNinth International EDI-IOS Conference, Bled, Slovenia.

24. Baber A, Thurasamy R, Malik MI, Sadiq B, Islam S, Sajjad M (2016) Online word-of-mouth antecedents, attitude and intention-to-purchase electronic products in Pakistan. Telematics and Informatics 33: 388-400.

25. Tan SJ (1999) Strategies for reducing consumer's risk aversion in Internet shopping. Journal of Consumer Marketing 16: 163-178.

26. Shah MH, Peikari HR, Yasin NM (2014) The determinants of individuals' 
Citation: Abrar K, Naveed M, Ramay MI (2017) Impact of Perceived Risk on Online Impulse Buying Tendency: an Empirical Study in the Consumer Market of Pakistan. J Account Mark 6: 246. doi: 10.4172/2168-9601.1000246

perceived e-security: Evidence from Malaysia. International Journal of Information Management 34: 48-57.

27. Sweeney JC, Soutar GN, Johnson LW (1999) The role of perceived risk in the quality-value relationship: a study in a retail environment. Journal of Retailing 75: 77-105.

28. Egeln LS, Joseph JA (2012) Shopping cart abandonment in online shopping. Atlantic Marketing Journal 1: 1-14

29. Forsythe S, Liu C, Shannon D, Gardner LC (2006) Development of a scale to measure the perceived benefits and risks of online shopping. Journal of Interactive Marketing 20: 55-75.

30. Laroche M, Bergeron J, Goutaland C (2001) A three-dimensional scale of intangibility. Journal of Service Research 4: 26-38.

31. Akhlaq A, Ahmed E (2015) Digital commerce in emerging economies: Factors associated with online shopping intentions in Pakistan. International Journal of Emerging Markets, 10: 634-647.

32. Forsythe SM, Shi B (2003) Consumer patronage and risk perceptions in Internet shopping. Journal of Business Research 56: 867-875.

33. Bhatnagar A, Misra S, Rao HR (2000) On risk, convenience, and Internet shopping behavior. Communications of the ACM 43: 98-105.

34. Beneke J, Flynn R, Greig T, Mukaiwa M (2013) The influence of perceived product quality, relative price and risk on customer value and willingness to buy: a study of private label merchandise. Journal of Product \& Brand Management 22: $218-228$.

35. Lee MC (2009) Factors influencing the adoption of internet banking: An integration of TAM and TPB with perceived risk and perceived benefit. Electronic Commerce Research and Applications 8: 130-141.

36. Crespo AH, del Bosque IR, de los Salmones Sanchez MG (2009) The influence of perceived risk on Internet shopping behavior: a multidimensional perspective. Journal of Risk Research 12: 259-277.
37. Raza SA, Hanif N (2013) Factors affecting internet banking adoption among internal and external customers: a case of Pakistan. International Journal of Electronic Finance 7: 82-96.

38. Moshrefjavadi MH, Dolatabadi HR, Nourbakhsh M, Poursaeedi A, Asadollah A (2012) An analysis of factors affecting on online shopping behavior of consumers. International Journal of Marketing Studies 4: 81.

39. Sun T, Wu G (2011) Trait predictors of online impulsive buying tendency: A hierarchical approach. Journal of Marketing Theory and Practice 19: 337-346.

40. Rezaei S, Ali F, Amin M, Jayashree S (2016) Online impulse buying of tourism products: The role of web site personality, utilitarian and hedonic web browsing Journal of Hospitality and Tourism Technology 7: 60-83.

41. Wright LT, Crimp M (1995) The marketing research process. Prentice Hall.

42. Fricker RD, Schonlau M (2002) Advantages and disadvantages of Internet research surveys: Evidence from the literature. Field methods 14: 347-367.

43. Nunnally JC (1978) Psychometric Theory (2nd edn.), McGraw-Hill. Hillsdale, NJ.

44. Choi J, Lee KH (2003) Risk perception and e-shopping: a cross-cultural study. Journal of Fashion Marketing and Management: An International Journal 7: 49-64.

45. Sinha P, Singh S (2014) Determinants of consumers' perceived risk in online shopping: a study. Indian Journal of Marketing 44: 22-32.

46. Verplanken B, Herabadi A (2001) Individual differences in impulse buying tendency: Feeling and no thinking. European Journal of Personality 15(S1).

47. Ozen H, Engizek N (2014) Shopping online without thinking: being emotional or rational? Asia Pacific Journal of Marketing and Logistics 26: 78-93.

48. Swinyard WR, Smith SM. Why people (don't) shop online: A lifestyle study of the internet consumer. Psychology \& Marketing 20: 567-597. 